\title{
Palliative radiotherapy to maintain outpatient status in elderly patients with esophageal carcinoma
}

\author{
Kenjiro Ishii, Yasuhiro Tsubosa, Masahiro Niihara, Toshiya Akai, Wataru Soneda \\ Department of Esophageal Surgery, Shizuoka Cancer Center, 1007 Shimonagakubo, Nagaizumi-cho, Suntou-gun, Shizuoka, Japan \\ Contributions: (I) Conception and design: K Ishii, Y Tsubosa; (II) Administrative support: Y Tsubosa; (III) Provision of study materials or patients: All \\ authors; (IV) Collection and assembly of data: K Ishii, W Soneda, T Akai; (V) Data analysis and interpretation: K Ishii; (VI) Manuscript writing: All \\ authors; (VII) Final approval of manuscript: All authors. \\ Correspondence to: Kenjiro Ishii, MD, PhD. Department of Esophageal Surgery, Shizuoka Cancer Center, 1007 Shimonagakubo, Nagaizumi-cho, \\ Suntou-gun, Shizuoka 411-8777, Japan. Email: tomukuru-zu@hotmail.co.jp.
}

\begin{abstract}
Background Radiation monotherapy effectively relieves symptoms of esophageal cancer. Many studies have reported relief from dysphagia with this treatment; however, the degree of the dysphagia is subjective. On the other hand, the length of outpatient management is objective. In this study, we investigated how radiation monotherapy can contribute to helping elderly patients with esophageal cancer remain as outpatients.
\end{abstract}

Methods: Between January 2010 and December 2017, we followed 42 patients aged >75 years who underwent radiation monotherapy for esophageal carcinoma. Of these patients, 36 were included in the study. We retrospectively collected data on the patients' characteristics, tumor extension around the circumference of the esophagus, medical procedures, prognosis, cause of death, and outpatient management period. We also analyzed the relationships between the outpatient management period, the clinical stage, and the circumferential extension of the tumor.

Results: Of the 36 patients (26 males, 10 females), 27 were treated using doses of 60 or 66 Gy, and 9 received 40 or 50 Gy. The median survival period of the patients who died during the study was 14 months, and their median period of outpatient management was 9 months. Eight of the 12 patients with tumors extending across four-fifths or the entire circumference of the esophagus required medical intervention to administer nutrition. There were no significant differences in the period of outpatient management among the patients who died during the study in terms of clinical stage and horizontal location.

Conclusions: Radiation monotherapy may facilitate outpatient management; however, patients with tumors extending all or most of the circumference of the esophagus required an additional medical procedure.

Keywords: Ambulatory care; elderly; esophageal cancer; palliative care; radiation

Submitted Dec 29, 2019. Accepted for publication Apr 09, 2020.

doi: 10.21037/apm-19-666

View this article at: http://dx.doi.org/10.21037/apm-19-666

\section{Introduction}

Esophageal cancer is common in the elderly and occurs more frequently in aging populations (1). Globally, the median age of patients with esophageal cancer is 67 years at diagnosis, with $30 \%$ of the patients aged $\geq 75$ years. Surgical resection is the standard treatment for esophageal cancer (2).
However, elderly patients or patients who have severe organ dysfunction require nonsurgical treatment. Currently, chemoradiotherapy (CRT) is the standard nonsurgical treatment; however, it may provoke more acute adverse events when compared with radiation therapy (RT) alone in high-risk patients (3). For these patients, palliative tumor 


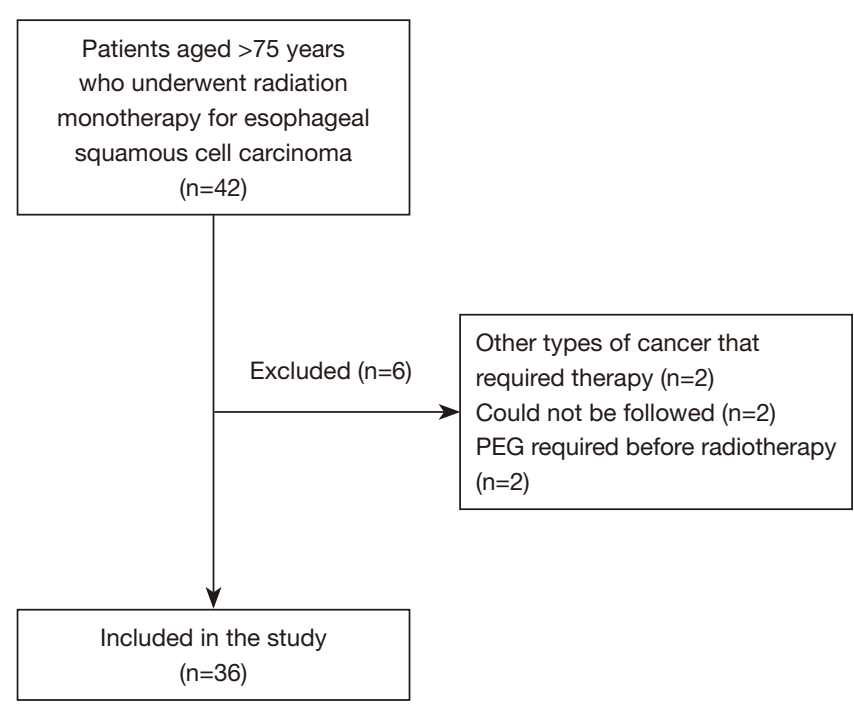

Figure 1 Study patients. Forty-two patients aged $>75$ years who underwent radiation monotherapy were followed, and 6 were excluded.

control is more important than curing the cancer and may improve the quality of life (QoL).

Many factors determine QoL, and an important aspect is outpatient treatment when possible. Methods for palliative therapy of esophageal cancer are well established, such as radiotherapy, percutaneous endoscopic gastrostomy (PEG), and a self-expanding metallic stent (SEMS). Radiotherapy is an effective and noninvasive therapy for the palliation of dysphagia with tumor shrinkage $(4,5)$, and improving dysphagia can extend the outpatient management period.

Several studies have reported data about the outcome (overall survival and progression-free survival) of RT alone in high-risk patients (6-8). While some studies have shown the effectiveness of radiation monotherapy for improving dysphagia $(4,5)$, few have reported the actual outpatient treatment period for high-risk, elderly, esophageal cancer patients who underwent radiation monotherapy.

The present study investigated the outpatient management period for these patients and the relationship between the outpatient management period, the clinical stage, and the tumor circumference. We also evaluated the clinical course and mortality of the patients.

\section{Methods}

This was a retrospective study conducted at the Shizuoka
Cancer Center in Japan. The study was approved by the independent medical ethics committee of the Shizuoka Cancer Center (No. 30-J15). Informed consent was not necessary due to the retrospective nature and observational design of the study.

Between January 2010 and December 2017, we followed 42 patients aged $>75$ years who underwent radiation monotherapy for esophageal carcinoma. Patients with histologically confirmed squamous cell carcinoma or esophageal adenocarcinoma and those who were medically unsuitable for radical treatment, including those with carcinoma that was too advanced for radical treatment, were eligible for the study. From the 42 original patients, six were excluded, including those who had other types of cancer that required different therapies, those who could not be followed up with, or those who required PEG prior to radiotherapy (Figure 1).

We retrospectively collected data on the patients' characteristics, tumor extension around the circumference of the esophagus, medical procedures, prognosis, cause of death, and outpatient management period. We also analyzed the relationships between the outpatient management period, the clinical stage, and the circumferential extension of the tumor.

\section{Statistical analysis}

The continuous variables are expressed as median or mean values with standard deviation or range. The differences were considered statistically significant when $\mathrm{P}<0.05$.

\section{Results}

\section{Patients' characteristics}

The clinical characteristics of the patients are presented in Table 1 . There were 26 males and 10 females, with a median age of 81 years (range, 75-91 years). Eight patients were aged $>85$ years. The primary lesions were predominantly located in the middle thoracic esophagus (19 cases, 52.8\%). Clinical staging (UICC 7th) was as follows: stages I, II, III, and IV were found in 9, 9, 14, and 4 cases, respectively, whereas the T-factor T1b, T2, T3, and T4a, b were found in $6,5,20$, and 5 cases, respectively (Table 1).

\section{Endoscopic findings prior to treatment}

Nine of the cases had tumors that spread across the entire 
Table 1 Patients' characteristics

\begin{tabular}{|c|c|}
\hline Items & Values (total $n=36$ ) \\
\hline Male/female & $26 / 10$ \\
\hline Age (years), median (range) & 81 (75 to 91$)$ \\
\hline \multicolumn{2}{|l|}{ Tumor staging (UICC 7th), $\mathrm{n}$} \\
\hline cStage IA & 5 \\
\hline cStage IB & 4 \\
\hline cStage IIA & 7 \\
\hline cStage IIB & 2 \\
\hline cStage IIIA & 6 \\
\hline cStage IIIB & 4 \\
\hline cStage IIIC & 4 \\
\hline cStage IV & 4 \\
\hline \multicolumn{2}{|l|}{ Tumor location, $\mathrm{n}$} \\
\hline $\mathrm{Ce}$ & 2 \\
\hline Ut & 2 \\
\hline Mt & 19 \\
\hline $\mathrm{Lt}$ & 11 \\
\hline $\mathrm{Ae}$ & 2 \\
\hline \multicolumn{2}{|l|}{ Horizontal location, $\mathrm{n}$} \\
\hline$>4 / 5$ of circumference & 13 \\
\hline Entire circumference & 9 \\
\hline$<4 / 5$ of circumference & 23 \\
\hline
\end{tabular}

circumference of the esophagus, and 13 of the patients had extension of the tumor over four-fifths of the circumference. In four of the cases with a whole-circumference lesion, only a small-diameter scope (GIF-XP 290; Olympus Corp.) could be passed through the esophagus. In one case, the scope could not be passed through at all (Table 1).

\section{Radiation monotherapy}

All of the patients underwent external beam radiotherapy, once a day, five times per week. All of the patients received three-dimensional conformal RT using a computed tomographic simulation with a thin slice. A total of 27 patients received a dose of $60 \mathrm{~Gy}$ in 30 fractions, 4 patients received a dose of 50 Gy in 25 fractions, and 5 patients received a dose of 40 Gy in 20 fractions (Table S1).
Table 2 Patients' prognosis

\begin{tabular}{lc}
\hline Condition & Values \\
\hline Alive & 5 \\
Age (years), median (range) & 80 (75-87) \\
Survival period (months), median (IQR 25-75) & $33(32-43)$ \\
cStage IB & 2 \\
cStage IIA & 1 \\
cStage IIB & 1 \\
cStage IIIA & 1 \\
Dead & 31 \\
Survival period (months), median (IQR 25-75) & $14(9-19)$ \\
Death due to esophageal cancer & 26 \\
Death due to other disease & 5 \\
Sudden death at home & 2 \\
COPD exacerbation & 1 \\
Urinary tract infection & 1 \\
Natural causes & 1 \\
\hline COPD, chronic obstructive pulmonary disease; IQR, interquartile \\
range.
\end{tabular}

\section{Requirement of a medical procedure for administration of nutrition}

Five of the patients required PEG, three of the patients required SEMS implantation, and one of the patients required the implantation of a totally implantable central venous access device. Overall, 7 of the 13 patients with a tumor extending across four-fifths to the entire circumference of the esophagus required a medical procedure (Table S1).

\section{Prognosis and period of ambulatory management}

At the writing of this paper, five of the patients were still alive, and the median survival period of the other 31 patients who died was 14 months. Of the five patients who passed away due to intercurrent disease, two of the patients aged $>85$ years suffered sudden death at home (Table 2).

The median period of outpatient management of the patients who died was 9 (6.0-17.5) months (Table 3). The most common cause of admission was deterioration of performance status, because of obstruction to the passage 
Table 3 Period of ambulatory management (months)

\begin{tabular}{|c|c|c|}
\hline Factors & Values & $\mathrm{P}$ \\
\hline Total (median, IQR 25-75) & $9.0(6.0-17.5)$ & - \\
\hline Clinical stages & & n.s. \\
\hline cStage I & $18(14.0-20.0)$ & \\
\hline cStage II & $6(5.0-14.0)$ & \\
\hline cStage III & $12(7.0-17.0)$ & \\
\hline cStage IV & $6(4.3-9.8)$ & \\
\hline Horizontal location & & n.s. \\
\hline $\begin{array}{l}>4 / 5 \text { of the circumference } \\
\text { (median, IQR } 25-75 \text { ) }\end{array}$ & $7.0(4.25-15.75)$ & \\
\hline $\begin{array}{l}<4 / 5 \text { of the circumference } \\
\text { (median, IQR 25-75) }\end{array}$ & $13.0(7.0-18.0)$ & \\
\hline
\end{tabular}

$I Q R$, interquartile range; n.s., no significant difference

with food and dyspnea (due to pneumonia or chronic obstructive pulmonary disease). There were no significant differences in clinical stage and horizontal location of the tumor (less than or more than four-fifths of the circumference of the esophagus) (Table 3).

\section{Discussion}

In many studies, the treatments used to relieve esophageal cancer symptoms were individualized and included various combinations of stent placement, chemotherapy, and RT (9). Effective relief of symptoms was reported in many randomized and nonrandomized clinical trials. Almost all of the studies reported relief from dysphagia $(10,11)$; however, the degree of dysphagia was subjective. On the other hand, maintaining outpatient status for the elderly is another important factor and is a comprehensive indication of QoL. This current study focused on the period of outpatient management because it is objective.

We targeted older adults aged $\geq 75$ years who had undergone radiation monotherapy for esophageal carcinoma. Due to the presence of several risk factors, radical treatment was not appropriate or desired by most of these patients. However, almost all of the patients underwent radiation monotherapy as planned.

In the present study, patients with tumors extending across four-fifths to the entire circumference of the esophagus required a further medical procedure, such as SEMS or PEG, due to stenosis of the treated area. However, contrary to expectations, there were no significant differences in the outpatient management period. Some studies have reported that stenting combined with RT is more effective for dysphagia relief than stenting alone. The overall survival was longer after additional RT, there was no treatment-related mortality, and the complications were similar in the stent-alone group and the stent plus RT group (12). Few studies have reported the relationship between circumferential extension and radiation monotherapy. The present study found that appropriate application of RT and additional medical procedures could even enable adults aged $>75$ years with almost wholecircumference esophageal carcinoma to achieve outpatient status, similar to those with a smaller carcinoma.

Contrary to expectations, there was no significant difference in the outpatient management period during each clinical stage. The use of RT monotherapy and additional medical procedures may enable patients with high-stage esophageal carcinoma to live at home for the same period as those with a low-stage disease. It is important to introduce sufficient home care to patients at the earliest possible time and help their families understand home care.

The patients who died suddenly at home were all aged $>85$ years. This may imply that, even if RT alone is performed in very elderly patients, the indications must be carefully judged.

The present study has some limitations. First, this retrospective study was conducted at a single center and was limited to a Japanese population. In addition, a QoL questionnaire was not applied, and we were unable to evaluate details about the home lives of the patients.

\section{Conclusions}

In conclusion, RT monotherapy could confer an adequate ambulatory status alone. In patients with almost wholecircumference esophageal carcinoma, RT monotherapy may have the same effect with the addition of other medical procedures and may be useful for elderly patients who require palliative care rather than a cure.

\section{Acknowledgments}

Funding: None.

\section{Footnote}

Conflicts of Interest: All authors have completed the ICMJE uniform disclosure form (available at http://dx.doi. 
org/10.21037/apm-19-666). The authors have no conflicts of interest to declare.

Ethical Statement: The authors are accountable for all aspects of the work in ensuring that questions related to the accuracy or integrity of any part of the work are appropriately investigated and resolved. The study was conducted in accordance with the Declaration of Helsinki (as revised in 2013). This study was approved by the institutional human ethics committee of Shizuoka Cancer Center (Shizuoka, Japan) (No. 30-J15), and it was performed in accordance with institutional ethics committee guidelines. Informed consent was not necessary due to the retrospective nature and observational design of the study.

Open Access Statement: This is an Open Access article distributed in accordance with the Creative Commons Attribution-NonCommercial-NoDerivs 4.0 International License (CC BY-NC-ND 4.0), which permits the noncommercial replication and distribution of the article with the strict proviso that no changes or edits are made and the original work is properly cited (including links to both the formal publication through the relevant DOI and the license). See: https://creativecommons.org/licenses/by-nc-nd/4.0/.

\section{References}

1. Howlader N, Noone AM, Krapcho M, et al. SEER cancer statistics review, 1975-2012, National Cancer Institute. Based on November 2014 SEER data submission, posted to the SEER web site. Available online: http://seer.cancer. gov/csr/1975_2012/

2. Ando N, Kato H, Igaki H, et al. A randomized trial comparing postoperative adjuvant chemotherapy with cisplatin and 5-fluorouracil versus preoperative chemotherapy for localized advanced squamous cell carcinoma of the thoracic esophagus (JCOG9907). Ann Surg Oncol 2012;19:68-74.

3. Okawa T, Dokiya T, Nishio M, et al. Multiinstitutional

Cite this article as: Ishii K, Tsubosa Y, Niihara M, Akai T, Soneda W. Palliative radiotherapy to maintain outpatient status in elderly patients with esophageal carcinoma. Ann Palliat Med 2021;10(2):1779-1783. doi: 10.21037/apm-19-666 randomized trial of external radiotherapy with and without intraluminal brachytherapy for esophageal cancer in Japan. Japanese Society of Therapeutic Radiology and Oncology (JASTRO) Study Group. Int J Radiat Oncol Biol Phys 1999;45:623-8.

4. Suzuki G, Yamazaki H, Aibe N, et al. Palliative radiotherapy in the local management of stage IVB esophageal cancer: factors affecting swallowing and Survival. Anticancer Res 2017;37:3085-92.

5. Welsch J, Kup PG, Nieder C, et al. Survival and symptom relief after palliative radiotherapy for esophageal cancer. J Cancer 2016;7:125-30.

6. Walter F, Böckle D, Schmidt-Hegemann NS, et al. Clinical outcome of elderly patients ( $\geq 70$ years) with esophageal cancer undergoing definitive or neoadjuvant radio(chemo)therapy: a retrospective single center analysis. Radiat Oncol 2018;13:93.

7. Shirakawa Y, Noma K, Maeda N, et al. Outcome of radiation monotherapy for high-risk patients with Stage I esophageal cancer. Acta Med Okayama 2017;71:127-33.

8. Zhou YC, Chen LL, Xu HB, et al. Aging-related prognosis analysis of definitive radiotherapy for very elderly esophageal cancer. Cancer Med 2018;7:1837-44.

9. Amdal CD, Jacobsen AB, Guren MG, et al. Patientreported outcomes evaluating palliative radiotherapy and chemotherapy in patients with oesophageal cancer: a systematic review. Acta Oncol 2013;52:679-90.

10. Amdal CD, Jacobsen AB, Sandstad B, et al. Palliative brachytherapy with or without primary stent placement in patients with oesophageal cancer, a randomised phase III trial. Radiother Oncol 2013;107:428-33.

11. Zhu HD, Guo JH, Mao AW, et al. Conventional stents versus stents loaded with (125)iodine seeds for the treatment of unresectable oesophageal cancer: a multicentre, randomised phase 3 trial. Lancet Oncol 2014;15:612-9.

12. Javed A, Pal S, Dash NR, et al. Palliative stenting with or without radiotherapy for inoperable esophageal carcinoma: a randomized trial. J Gastrointest Cancer 2012;43:63-9. 


\section{Supplementary}

Table S1 External beam radiotherapy and medical procedure

\begin{tabular}{lc}
\hline Kinds of inteervention & Number \\
\hline External beam radiotherapy: radiation dose $(n=36)$ & 27 \\
60 Gy & 4 \\
50 Gy & 5 \\
40 Gy & 5 \\
Medical procedure for nutrition administration: kind of procedure $(n=9)$ & 3 \\
PEG & 1 \\
SEMS & \\
TIVAD &
\end{tabular}

PEG, percutaneous endoscopic gastrostomy; SEMS, self-expanding metallic stent; TIVAD, totally implantable central venous access device. 